Federal Reserve Bank of Minneapolis

Research Department

October 10, 2012

\title{
On the Social Usefulness of Fractional Reserve Banking *
}

\author{
V. V. Chari \\ University of Minnesota \\ Federal Reserve Bank of Minneapolis
}

Christopher Phelan

University of Minnesota

Federal Reserve Bank of Minneapolis

\begin{abstract}
This paper presents a simple means-of-payment-in-advance model where households can purchase the single consumption good with either deposits from a price taking representative bank or cash. We show that even if facilitating trade through deposits is physically costly, such trade occurs in equilibrium if banks face a low enough reserve ratio. Thus it is possible that fractional reserve banking occurs in the unique equilibrium, but is strictly dominated by the equilibrium associate with a $100 \%$ reserve ratio, even when bank runs are explicitly ruled out.
\end{abstract}

*The views expressed herein are those of the authors and not necessarily those of the Federal Reserve Bank of Minneapolis or the Federal Reserve System. 


\section{Introduction:}

Fractional reserve banking is, to put it mildly, problematic. Banks with fractional reserves have been historically subject to runs and panics with arguably enormous external effects. Further, banks are costly. Even abstracting from runs and panics (as we do in this paper), the banking sector uses up real resources - labor and capital — which could be put to alternative uses. But fractional reserve banking is also ubiquitous. It appears to occur throughout history, with our without bailouts, making it difficult to argue that this ubiquity is due simply to bailouts or government subsidies. Usually, the ubiquity of an economic arrangement itself argues that this arrangement serves a valuable social purpose. Historically, one such purpose is that banks have allowed individuals and firms to pay for goods and services through their provision of bank checks and other widely accepted claims. Therefore, those individuals and firms haven't had to resort to costly barter or non-interest bearing specie trade.

In this paper, we raise the possibility that this facilitation of trade using interest bearing deposits serves a privately useful function, while providing lower (and perhaps negative) social benefits. In one simple example we provide, banks are worse than useless in that they use up real resources but provide no societal benefit, and this is true even when we explicitly rule out significant societal costs such as bank runs. The more general point we wish to make is that the private benefits from creating private payments systems may exceed the social benefits.

In this paper's model, bank provision of payments services through demand deposits results in private decisions by households to use these lower-private-cost deposits rather than higher-privatecost cash, and that doing so increases the money supply. This extra money increases prices generally, an external cost that no household takes into account when choosing between holding cash or holding deposits in making transactions. This divergence between private and social costs is thus the wasteful result of bank-provided payments services. 
Our paper is related to a large literature in money and banking. Our paper has in common with Aiyagari, Braun, and Eckstein (1998) that private money creation uses real resources so that inflation stimulates the demand for private money and has real costs. They focus on the welfare costs of inflation while our focus is on examining the benefits and costs of changes in reserve requirements. Our paper is also related to Monnet and Sanches (2011) who show, among other results, that 100\% reserve requirements may be undesirable. Their result derives from lack of commitment of bankers to repay depositors. We also show that $100 \%$ reserve requirements may be undesirable, but our results derive from comparing the costs of private money creating versus the insurance benefits associated with private money.

Other papers, see for example Gu et.al. (2012) have developed theories of banking using mechanism design approaches. Almost by construction, such theories imply that allocations are efficient. While we believe such an approach is very useful, in our paper we focus on inefficiencies that could arise when private and social interests do not coincide.

Finally, our paper is related to an extensive literature on so called "pecuniary externalities" that arise when prices enter consumption or production sets. See, for instance, Kehoe and Levine (1993), Kiyotaki and Moore (1997), Lorenzoni (2008), and Hart and Zingales (2011). Perhaps the most closely related of these is Hart and Zingales (2011) who develop a four-period model in which they argue that private liquidity provision can be inefficiently high due to a pecuniary externality. They do not analyze the welfare effects of fractional reserve banking.

\section{The Model:}

The model is a simple, infinitely repeated, means-of-payment-in-advance economy. There exists a unit continuum of identical households, a single price-taking representative bank, and a monetary authority whose sole function is to (possibly) make lump sum monetary transfers to households. Time is discrete and is denoted $t \in\{0,1,2, \ldots\}$. 
The commodities in the economy are a single, divisible, non-storable consumption good, of which each household receives a constant endowment $y$, and a commodity which we refer to as "gold". Gold can take three forms: coins $(m)$, which can be used to facilitate trade, gold bars $\left(g^{b}\right)$, which can be used by the bank as reserves, and jewelry $\left(g^{h}\right)$, which brings direct enjoyment to the owner. At the beginning of each period, gold can be linearly and costlessly transformed across its three forms. Thus for each date $t \geq 0$,

$$
m_{t}+g_{t}^{h}+g_{t}^{b}=G_{t}
$$

where $G_{t}$ is the aggregate supply of gold at date $t$. We assume $G_{0}=1$ and $G_{t+1}=(1+\eta) G_{t}$.

At each date $t$, the bank is assumed to be able to freely create deposits, $d_{t}$, subject to a constraint that $\alpha d_{t} \leq g_{t}^{b}$, where $g_{t}^{b}$ is the bank's holdings of gold, and $\alpha$ is a reserve ratio.

Households cannot eat their own endowments but must instead trade with other households. If such trade occurs using coins, (the selling household receives coins in exchange for the consumption good), we assume it occurs costlessly. If such trade occurs using bank deposits, (the selling household receives bank deposits in exchange for the consumption good), we assume it occurs with a physical cost $\phi$ in terms of the consumption good. Specifically, if a household wishes to consume $c$ units of the consumption good and purchase these goods with deposits, it must actually purchase $(1+\phi) c$ units of the consumption good, where $\phi c$ units of the consumption are used up facilitating the trade. Presumably, this cost $\phi$ stands in for the real resources (labor and capital) of running a banking system. Formally, it is simply an iceberg cost.

Households care about streams of consumption and (possibly) jewelry holdings according to the per-period utility function

$$
U\left(c_{t}, \theta_{t}\right)+v\left(g_{t}^{h}\right)
$$


where $c_{t}$ is consumption, $\theta_{t} \in \Theta$ is a publicly observed ideosyncratic i.i.d. preference shock, and $g^{h}$ is gold held by the household in non-monetary form (jewelry). If $v\left(g^{h}\right)=0$ for all $g^{h}$, then gold is interpreted as a fiat currency. So that a stationary equilibrium exists we assume

Assumption 1. Either $v\left(g^{h}\right)=0$ for all $g^{h}$ (fiat currency) or $G_{t}=1$ for all $t$ ( $\eta=0$ or gold is in fixed supply).

\section{A. Markets:}

At the beginning of each period, $t$, households can freely transform gold between coins and jewelry, and there exists a market among households and the bank with trade in gold, deposits, and promises to deliver gold at the beginning of the next period contingent on the (yet to be realized) taste shock $\theta_{t}$. Let $q_{t}\left(\theta_{t}\right)$ be the price of claim to a unit of $\theta_{t}$-contingent gold next period and let $x_{t}\left(\theta_{t}\right)$ denote the quantity of $\theta_{t}$-contingent gold a household purchases. (If $x_{t}\left(\theta_{t}\right)<0$, then the household has sold a promise to deliver gold if his taste shock turns out to be $\theta_{t}$.) Also assume households are free at this point to obtain gold directly from the bank, one for one, by presenting deposits to the bank. That is, a deposit is considered to be a legal right to trade deposits for gold with the bank, one-for-one. Households may also give gold to the bank in return for deposits, again, one-for-one, if the bank chooses to create the deposit. We further assume, as part of this market structure, that a deposit entails a legal requirement on the bank to pay a market determined rate of interest, $r_{t}$, to the depositor, one period later. These assumptions deliver the household budget constraint in this market as

$$
m_{t}+d_{t}+g_{t}^{h}+\sum_{\theta_{t}} q_{t}\left(\theta_{t}\right) x_{t}\left(\theta_{t}\right) \leq w_{t}
$$

where $w_{t}$ is the household's beginning of period wealth in terms of coins, deposits and jewelry.

After the financial markets close, each household receives its endowment of $y$ units of the 
consumption good and realizes its i.i.d. preference shock $\theta \in \Theta$. (Let $\pi\left(\theta_{t}\right)$ denote the fraction of households with shock $\theta_{t}$.) Households then split into shopper-seller pairs.

Sellers inelastically supply y units to market. Shoppers buy the consumption good using either deposits or gold coins, where $p_{t}^{c}$ is the price of consumption in terms of either form of payment. Let $c_{t}^{m}\left(\theta_{t}\right)$ denote the consumption purchases of a type $\theta_{t}$ using coins and $c_{t}^{d}\left(\theta_{t}\right)$ denote the consumption purchases of a type $\theta_{t}$ household using deposits. Shoppers face means-of-payment-in-advance constraints that

$$
p_{t}^{c} c_{t}^{m}\left(\theta_{t}\right) \leq m_{t}
$$

and

$$
p_{t}^{c}(1+\phi) c_{t}^{d}\left(\theta_{t}\right) \leq d_{t}
$$

Note that the timing does not allow the household's allocation of its wealth between coins, deposits, and jewelry to depend on its preference shock $\theta$. After trade, households eat and receive utility $u\left(c_{t}^{m}\left(\theta_{t}\right)+c_{t}^{d}\left(\theta_{t}\right), \theta_{t}\right)+v\left(g_{t}^{h}\right)$.

At the end of period $t$, households receive transfers $x_{t}\left(\theta_{t}\right)$, interest on deposits $r_{t} d_{t}$ and a lump-sum gold transfer from the monetary authority $\eta$. (Note that interest is paid on deposits held before the market for the consumption good. This ensures that sellers equally value coins and deposits.) Thus a household starts period $t+1$ with wealth (per unit of date $t+1$ gold)

$$
w_{t+1}\left(\theta_{t}\right)=\frac{1}{1+\eta}\left(\eta+\left(1+r_{t}\right) d_{t}+g_{t}^{h}+m_{t}+x_{t}\left(\theta_{t}\right)+p_{t}^{c}\left(y-c_{t}^{m}\left(\theta_{t}\right)-(1+\phi) c_{t}^{d}\left(\theta_{t}\right)\right)\right) .
$$

\section{Allocations:}

An allocation (with prices) is a sequence

$$
\left\{c_{t}^{m}\left(\theta^{t}\right), c_{t}^{d}\left(\theta^{t}\right), m_{t}\left(\theta^{t-1}\right), d_{t}\left(\theta^{t-1}\right), g_{t}^{h}\left(\theta^{t-1}\right), x_{t}\left(\theta_{t}\right)\left(\theta^{t-1}\right), g_{t}^{b}, q_{t}(\theta), p_{t}^{c}, r_{t}\right\}_{t=0}^{\infty}
$$


An allocation is resource feasible if for all $t \geq 0$

$$
\sum_{\theta^{t}} \pi\left(\theta_{0}\right) \ldots \pi\left(\theta_{t}\right)\left(c^{m}\left(\theta^{t}\right)+(1+\phi) c^{d}\left(\theta^{t}\right)\right)=y
$$

and

$$
\sum_{\theta^{t-1}} \pi\left(\theta_{0}\right) \ldots \pi\left(\theta_{t-1}\right)\left(m_{t}\left(\theta^{t-1}\right)+g_{t}^{h}\left(\theta^{t-1}\right)\right)+g_{t}^{b}=1
$$

An allocation is a competitive equilibrium if it is resource feasible and solves the household and bank problems outlined below. To simplify somewhat, we only consider allocations where prices $p_{t}^{c}$, $r_{t}$, and $q_{t}(\theta)$ are all constants.

\section{A. Household Problem:}

Given constant prices, the household problem is recursive (in beginning of period wealth relative to the aggregate gold supply) and can be expressed as

$$
V(w) \equiv \max _{c^{m}(\theta), c^{d}(\theta), d, m, g^{h}, x(\theta)} \sum_{\theta} \pi(\theta)\left[u\left(c^{m}(\theta)+c^{d}(\theta), \theta\right)+v\left(g^{h}\right)+\beta V\left(w^{\prime}(\theta)\right)\right]
$$

subject to

$$
\begin{gathered}
m+d+g^{h}+\sum_{\theta} q(\theta) x(\theta) \leq w \\
p_{c} c^{m}(\theta) \leq m, \\
p_{c}(1+\phi) c^{d}(\theta) \leq d, \\
w^{\prime}(\theta)=\frac{1}{1+\eta}\left(\eta+(1+r) d+g^{h}+m+x(\theta)+p^{c}\left(y-c^{m}(\theta)-(1+\phi) c^{d}(\theta)\right)\right) .
\end{gathered}
$$


as well as conditions that all choice variables other than $x(\theta)$ be non-negative. Let $\mu$ be the Lagrange multiplier on the budget constraint (??) and $\pi(\theta) \gamma^{m}(\theta)$ and $\pi(\theta) \gamma^{d}(\theta)$ be the Lagrange multipliers on the cash in advance constraints (??) and (??).

\section{B. Bank Problem:}

At all dates, the representative bank is free to create deposits, $d_{t}$, subject to the constraint that $\alpha d_{t} \leq g_{t}^{b}$, where $g_{t}^{b}$ is the banks reserve holdings of gold. Further, the creation of a deposit $d_{t}$ obligates the bank to pay $r d_{t}$ to the depositor at all future dates starting at date $t+1$ (assuming, without loss, that the deposit is never destroyed.) Thus a choice of $\left(d_{t}, g_{t}^{b}\right)$ must solve

$$
\max _{d_{t}} d_{t}-g_{t}^{b}-\frac{q}{1-q} d_{t}
$$

subject to $\alpha d_{t} \leq g_{t}^{b}$, where $q \equiv \sum_{\theta} q(\theta)$, or the unconditional price at date $t$ to a unit of gold at date $t+1$.

\section{Stationary Equilibria:}

To characterize stationary equilibria (equilibria with constant prices), first consider the first order condition with respect to $x(\theta)$ in the household problem, or

$$
\beta \pi(\theta) V^{\prime}\left(w^{\prime}(\theta)\right) \frac{1}{1+\eta}=q(\theta) \mu
$$

If $q(\theta)=\beta \pi(\theta) /(1+\eta)$, this becomes

$$
V^{\prime}\left(w^{\prime}(\theta)\right)=\mu
$$

for all $\theta$. Thus given $q(\theta)=\beta \pi(\theta) /(1+\eta), w^{\prime}(\theta)$ is independent of $\theta$. Further, standard envelope arguments imply $V^{\prime}(w)=\mu$, thus

$$
V^{\prime}\left(w^{\prime}(\theta)\right)=V^{\prime}(w)
$$


for all $\theta$, which implies $w^{\prime}(\theta)=w$ for all $\theta$. In words, when $q(\theta)=\beta \pi(\theta) /(1+\eta)$, a condition of household optimization is that household wealth is constant over all dates and all histories of preference shocks. That

$$
q(\theta)=\beta \pi(\theta) /(1+\eta)
$$

is from now on imposed.

Next, consider the implications of profit maximization by the representative bank. If one substitutes that bank's reserve requirement, $\alpha d_{t} \leq g_{t}^{b}$, at equality into its objective function (??) it becomes

$$
d\left[1-\alpha-\frac{q}{1-q} r\right]
$$

which is linear in $d$. Thus a necessary condition for maximization (which also implies zero profits) is that the bracketed expression in (??) equal zero, or

$$
r=(1-\alpha)\left(\frac{1}{q}-1\right)=(1-\alpha)\left(\frac{1+\eta}{\beta}-1\right)
$$

or that the interest rate on deposits equals $(1-\alpha)$ times the nominal interest rate.

\section{A. Further Characterization}

Proposition 1. There exists a cutoff interest rate on deposits $r^{*}=\frac{(1+\eta) \phi}{\beta(1+\phi)}$ such that if $r>r^{*}$, household optimization implies $m=0$ and $c^{m}(\theta)=0$ for all $\theta$ and if $r<r^{*}, d=0$ and $c^{d}(\theta)=0$ for all $\theta$.

Proof. Consider the household problem. The first order condition with respect to $d$ (ignoring nonnegativity and imposing (??)) delivers

$$
\left(1-\beta \frac{1+r}{1+\eta}\right) \mu=\sum_{\theta} \pi(\theta) \gamma^{d}(\theta) .
$$


Let $c(\theta)=c^{d}(\theta)+c^{m}(\theta)$. The first order condition with respect to $c^{d}(\theta)$ and imposing (??) delivers

$$
u_{c}(c(\theta), \theta)=p_{c}(1+\phi)\left(\frac{\beta \mu}{1+\eta}+\gamma^{d}(\theta)\right)
$$

which implies

$$
\sum_{\theta} \pi(\theta) u_{c}(c(\theta), \theta)=p_{c}(1+\phi)\left(\frac{\beta \mu}{1+\eta}+\sum_{\theta} \pi(\theta) \gamma^{d}(\theta)\right)
$$

Together, (??) and (??) imply

$$
\sum_{\theta} \pi(\theta) u_{c}(c(\theta), \theta)=p_{c}(1+\phi) \mu\left(1-\frac{\beta r}{1+\eta}\right)
$$

Next, the first order condition with respect to $m$ (again ignoring non-negativity and imposing (??)) delivers

$$
\left(1-\frac{\beta}{1+\eta}\right) \mu=\sum_{\theta} \pi(\theta) \gamma^{m}(\theta)
$$

and the first order condition with respect to $c^{m}(\theta)$ and imposing (??) delivers

$$
u_{c}(c(\theta), \theta)=p_{c}\left(\frac{\beta \mu}{1+\eta}+\gamma^{m}(\theta)\right)
$$

which implies

$$
\sum_{\theta} \pi(\theta) u_{c}(c(\theta), \theta)=p_{c}\left(\frac{\beta \mu}{1+\eta}+\sum_{\theta} \pi(\theta) \gamma^{m}(\theta)\right)
$$

Together, (??) and (??) imply

$$
\sum_{\theta} \pi(\theta) u_{c}(c(\theta), \theta)=p_{c} \mu
$$

Note that the left hand sides of equation (??) and (??) are identical. Thus $m$ and $d$ can both be 
positive only if the right hand sides are equal or

$$
(1+\phi)\left(1-\frac{\beta r}{1+\eta}\right)=1
$$

Let $r^{*}$ solve (??) or

$$
r^{*}=\frac{(1+\eta) \phi}{\beta(1+\phi)}
$$

The result follows immediately.

An equilibrium with $d=0$ and $m>0$ is referred to as a cash equilibrium. An equilibrium with $d>0$ and $m=0$ is referred to as a banking equilibrium.

Corollary 1. There exists a cutoff reserve ratio $\alpha^{*} \equiv \frac{1+\eta-\beta(1+\phi)}{(1+\eta-\beta)(1+\phi)}$ such that if $\alpha>\alpha^{*}$, a banking equilibrium cannot exist, and if $\alpha<\alpha^{*}$, a cash equilibrium cannot exist.

Proof. Since $r$ is a function of the reserve ratio $\alpha$, one can solve for $\alpha^{*}$ - the cutoff reserve ratio by equating the right hand sides of (??) and (??) to derive

$$
\alpha^{*} \equiv \frac{1+\eta-\beta(1+\phi)}{(1+\eta-\beta)(1+\phi)}
$$

Corollary 2. If $\phi>\frac{1+\eta}{\beta}-1$ (or $\phi$ exceeds the nominal interest rate), then a banking equilibrium cannot exist. (In particular, if $\frac{1+\eta}{\beta}=1$, or the nominal interest rate equals zero, then a banking equilibrium cannot exist for any $\phi>0$.) If $\phi<\frac{1+\eta}{\beta}-1$ then there exists a sufficiently low reserve ratio $\alpha$ such that a banking equilibrium exists.

Proof. For households to be willing to transact using deposits, one needs $r \geq \frac{(1+\eta) \phi}{\beta(1+\phi)}$. For the 
representative bank to be willing to create deposits, it needs $r \leq(1-\alpha)\left(\frac{1+\eta}{\beta}-1\right)$. Thus one needs

$$
\frac{(1+\eta) \phi}{\beta(1+\phi)} \leq(1-\alpha)\left(\frac{1+\eta}{\beta}-1\right)
$$

Since the right hand side of (??) is decreasing in $\alpha$, setting $\alpha=0$ relaxes (??) as much as possible. Thus if $\frac{(1+\eta) \phi}{\beta(1+\phi)}>\frac{1+\eta}{\beta}-1$, which solves for $\phi>\frac{1+\eta}{\beta}-1$, banking is incompatible with either household optimization or non-negative profits for the representative bank for all $\alpha>0$. Likewise, if $\phi<\frac{1+\eta}{\beta}-1$, then $\alpha$ can be set low enough (but still positive) such that (??) can be satisfied.

\section{Welfare:}

If $v\left(g^{h}\right)=0$ for all $g^{h}$ (fiat money) and $\Omega$ is a singleton (no preference shocks), then characterization and welfare analysis is greatly simplified.

First, suppose $\alpha>\alpha^{*}$ and thus $d=0$. Bank optimization then implies $g^{b}=0$ (banks hold no reserves). That $v\left(g^{h}\right) \equiv 0$ implies $g^{h}=0$, and thus market clearing for gold (equation (??)) implies all gold is held as coins, or $m=1$, where the gold supply is normalized to unity each period. Goods market clearing implies $c=y$, and the cash-in-advance constraint implies $p^{c}=\frac{1}{y}$ (where $p^{c}$ is in terms of current period gold). That $m_{0}=1, m_{t+1}=(1+\eta) m_{t}, x_{t+1}=(1+\eta) x_{t}, q=\beta /(1+\eta)$ and $m_{t+1}+q x_{t+1}=m_{t}+\eta+x_{t}$ then implies $x_{t}=0$ for all $t \geq 0$.

Thus the stationary monetary equilibrium with fiat money and no preference shocks is quite simple. Each period, a household enters with wealth $w=1$ (where the current aggregate supply of gold is the numeraire) in the form of one gold coin. It makes no trades in the initial financial market. The household's shopper goes off and purchases $y$ units of the consumption good while the household's seller sells the household's endowment, $y$, for one gold coin. The household is then handed $\eta$ gold coins by the monetary authority. At the beginning of the next period, the household holds $(1+\eta)$ coins in terms of the previous period's numeraire, or one gold coin in terms of the 
current numeraire.

Next, suppose $\alpha<\alpha^{*}$ and thus $m=0$. As before, that $v\left(g^{h}\right) \equiv 0$ implies $g^{h}=0$, and thus market clearing for gold (equation (??)) implies all gold is held as bank reserves, or $g^{b}=1$ and $d=1 / \alpha$. Goods market clearing implies $(1+\phi) c=y$, and the cash-in-advance constraint, $p^{c}(1+\phi) c=d$ implies $p^{c}=\frac{1}{\alpha y}$. That $d_{0}=1 / \alpha, d_{t+1}=(1+\eta) d_{t}, x_{t+1}=(1+\eta) x_{t}, q=\beta /(1+\eta)$, $r=(1-\alpha)(1 / q-1)$ and $d_{t+1}+q x_{t+1}=d_{t}(1+r)+\eta+x_{t}$ then implies

$$
x=\frac{-(1-\alpha)}{\alpha} \frac{1+\eta}{\beta}<0
$$

Thus the stationary banking equilibrium can be described as follows: Each period, a household again enters the period with wealth $w=1$ in terms of the current gold supply. At the initial financial market, the household converts this wealth into a unit of deposits and borrows an additional $-q x$ from the bank, leaving the financial market with $d=1 / \alpha$ deposits and an obligation to pay the bank $-x$ at the end of the period. $(d=1-q x=1 / \alpha$ from the derived equilibrium values for $q$ and $x$ ). The household's shopper then goes off and purchases $y$ units of the consumption good (of which $y /(1+\phi)$ can be used for consumption) while the household's seller sells the household's endowment, $y$, for $1 / \alpha$ deposits. The household is then handed $\eta$ gold coins by the monetary authority, receives $r / \alpha$ interest on its deposits, and pays $-x$ to the bank, leaving it with wealth, in terms of the new gold supply of $w=(1 /(1+\eta))(\eta+(1 / \alpha)(1+r)+x)=1$.

Proposition 2. Suppose $v\left(g^{h}\right)=0$ for all $g^{h}$ (fiat money) and $\Omega$ is a singleton (no preference shocks). Then the cash equilibrium dominates the banking equilibrium (or the optimal policy is $\alpha=1)$.

Proof. In the cash equilibrium, steady state consumption is equal to $y$. In the banking equilibrium, steady state consumption is equal to $y /(1+\phi)$. 
A useful question is why a household doesn't deviate and use cash in the banking equilibrium, since its utility in the cash equilibrium is higher than in the banking equilibrium. The simple answer is that it can't afford to. Steady state wealth is the same $(w=1)$ in both equilibria. But the price level is $1 / \alpha$ times higher in the banking equilibrium, since the supply of "money" (assets which can be used for trade) is $1 / \alpha$ times higher in the banking equilibrium. Thus a household which used only cash and didn't borrow in the banking equilibrium could only afford $1 / p^{c}=\alpha y$ units of consumption in the first period. (In subsequent periods, the household could afford to purchase $y$ units of consumption each period.) Consuming $y /(1+\phi)$ units of the consumption good each period is preferable to consuming $\alpha y$ units in the first period, and $y$ units thereafter. Now this is not the only deviation where only cash is used. The deviating household could borrow from the bank, for instance, to smooth consumption and nevertheless only use cash. However, the point remains that that using cash in every period to purchase $y$ units of consumption as in the cash equilibrium is not in a household's constraint set when $p^{c}=1 / \alpha$. Further, the effect on the price level of the increase in the money supply induced by a household's decision to use deposits is external to that household. This externality, through the means-of-payment-in-advance constraints, is the source of the competitive equilibrium inefficiency.

Next, consider when $v\left(g^{h}\right) \neq 0$ or when $\Omega$ is not a singleton. (As before, assume if $v\left(g^{h}\right) \neq 0$, then $\eta=0$, so that a steady state equilibrium exists).

Proposition 3. If $\theta \in\{L, H\}$ and $\alpha>\alpha^{*}$, then steady state expected utility is independent of $\alpha$.

Proof. Equation (??) and $\gamma^{m}(L)=0$ with (??) implies

$$
\frac{\beta}{1+\eta} \sum_{\theta} \pi(\theta) u_{c}(c(\theta), \theta)=u_{c}(c(L), L)
$$


or,

$$
\frac{\beta}{1+\eta} \pi(H) u_{c}(c(H), H)=\left(1-\frac{\beta}{1+\eta} \pi(L)\right) u_{c}(c(L), L)
$$

This, along with

$$
\pi(L) c(L)+\pi(H) c(H)=y
$$

solve for $c(L)$ and $c(H)$ independently of $\alpha$.

To solve for $g^{h}$ (jewelry), note that the cash-in-advance constraint holding with equality for $\theta=H$ implies the real value of money, or

$$
p_{c} c(H)=m \text {. }
$$

The first order condition with respect to $g^{h}$ (jewelry) is

$$
v^{\prime}\left(g^{h}\right)=\left(1-\frac{\beta}{1+\eta}\right) \mu
$$

Finally, since $d=0, g^{b}=0$. Equations (??), (??), (??) and

$$
g^{h}+m=1
$$

then solve for $m, g^{h}, p_{c}$ and $\mu$ as functions of $c(L)$ and $c(H)$ (which, again, do not depend on $\alpha$ ). (If $v\left(g^{h}\right) \equiv 0$ for all $g^{h}$ (fiat money), then $g^{h}=0$ replaces equation (??)).

Proposition 4. If $\theta \in\{L, H\}$ and $\alpha<\alpha^{*}$, then steady state expected utility from consumption $\left(\sum_{\theta} \pi(\theta) u(c(\theta), \theta)\right)$ is decreasing in $\alpha$. If $v\left(g^{h}\right) \equiv 0$ for all $g^{h}$ (fiat money), then welfare is decreasing in $\alpha$ for all $\alpha<\alpha^{*}$. 
Proof. Equation (??) and $\gamma^{d}(L)=0$ with (??) implies

$$
\frac{\beta}{1+\eta} \sum_{\theta} \pi(\theta) u_{c}(c(\theta), \theta)=u_{c}(c(L), L)(1-\beta r)
$$

or,

$$
\frac{\beta}{1+\eta} \pi(H) u_{c}(c(H), H)=\left(1-\frac{\beta}{1+\eta} r-\frac{\beta}{1+\eta} \pi(L)\right) u_{c}(c(L), L)
$$

This, along with

$$
\pi(L) c(L)+\pi(H) c(H)=\frac{y}{1+\phi}
$$

solves for $c(L)$ and $c(H)$ as functions of $r$ (which is a decreasing function of $\alpha$ ). Note that if $\alpha=0$, $r=\left(\frac{1+\eta}{\beta}-1\right)$ and (??) implies $u_{c}(c(H), H)=u_{c}(c(L), L)$. In particular, as $\alpha$ increases (and $r$ decreases), aggregate consumption is unchanged but $u_{c}(c(L), L)$ decreases relative to $u_{c}(c(H), H)$, decreasing expected utility from consumption.

In words, the first of the previous two propositions states that if $\alpha>\alpha^{*}$ (or that the stationary equilibrium involves only cash), then the actual value of $\alpha$ is irrelevant. Intuitively, if the reserve ratio is high enough to shut down banking, increasing it further has no effects. The second states that if $\alpha<\alpha^{*}$ (or that the stationary equilibrium involves only deposits), then increasing $\alpha$ decreases welfare. Intuitively, if the reserve ratio is low enough to allow banking, decreasing it further increases welfare (or at least that part of welfare which comes from consumption and not jewelry). This occurs because decreasing the reserve ratio increases the equilibrium interest rate on deposits. This allows better insurance across $\theta$ shocks. In particular, if $\alpha=0$ (or, more carefully, as $\alpha \rightarrow 0$ from above to avoid an infinite price level) the equilibrium allocation has the interest rate on deposits equal the nominal interest rate in the credit market and thus mimics the non-cash-in-advance constrained allocation for the economy where each household's per period endowment is $y /(1+\phi)$. For higher 
values of $\alpha$ (but still low enough to allow banking), each household conserves on deposits (since there is an opportunity cost to holding wealth in the form of deposits), distorting the household's consumption choice $c^{d}(\theta)$.

This logic then allows a further (non) result: No welfare comparison can, in general, be made between the monetary equilibrium $\left(\alpha>\alpha^{*}\right)$ and the various banking equilibria (one for each $\alpha<\alpha^{*}$ ). If one considers, as a thought experiment, moving $\alpha$ from just above $\alpha^{*}$ to just below, several countervailing forces on welfare occur. First, consumption falls from $y$ per household to $y /(1+\phi)$ per household. This hurts welfare. But second, the interest rate on the equilibrium means-of-payment rises from zero (the interest rate on cash) to $r=\left(1-\alpha^{*}\right)((1+\eta) / \beta-1)>0$ - a discontinuous jump as a function of $\alpha$. This jump in the interest rate causes a discontinuous and welfare improving change in $c(\theta)$ for the reasons outlined in the previous paragraph. Finally, in the switch from the monetary equilibrium to the banking equilibrium, there is a discontinuous change (again as a function of $\alpha$ ) in the price of gold relative to consumption. If jewelry is valued $(v() \neq 0$.$) , this causes a discontinuous change in the steady state level of gold held as jewelry.$ Intuitively, fractional reserve banking allows fewer units of gold to be used facilitating trade and more units to be used in a form which directly increases utility.

\section{Conclusion:}

We have developed a model in which privately produced money provides a socially useful insurance role and a privately useful but socially costly medium of exchange. We have shown that if reserve requirements are sufficiently low then private money drives out specie as a medium of exchange. We have further shown that if the assets used to back private money have no direct value in preferences or technology and the social value of insurance is sufficiently small, equilibria with fractional reserve banking are necessarily inefficient. Finally, we have shown that if the assets used to back private money have no direct value in preferences or technology, then it is desirable to set 
reserve requirements either to zero or $100 \%$.

\section{References}

[1] Aiyagari, S. Rao; Braun, R. Anton; Eckstein, Zvi (1998). "Transaction Services, Inflation, and Welfare." Journal of Political Economy. 106 (6).

[2] Gu, C., Mattesini, F., Monnet, C., Wright, R. (2012) "Banking: A New Monetarist Approach." Review of Economic Studies, forthcoming.

[3] Hart, A. and L. Zingales. (2011) "Inefficient Provision of Liquidity." manuscript. University of Chicago.

[4] Kehoe, T. and D. Levine "Debt-Constrained Asset Markets." The Review of Economic Studies, Vol. 60, No. 4 (Oct., 1993), pp. 865-888

[5] Kiyotaki, N. and J. Moore. (1997) "Credit Cycles." Journal of Political Economy 105, 211-248.

[6] Lorenzoni, G. (2008) "Inefficient Credit Booms," Review of Economic Studies, vol. 75(3), pages 809-833.

[7] Monnet, C. and D. Sanches (2011) "Private Money and Banking Regulation."manuscript. Federal Reserve Bank of Philadelphia. 